\title{
Bioethics of the refusal of blood by Jehovah's Witnesses: part 3. A proposal for a don't-ask-don't-tell policy
}

\author{
Osamu Muramoto Kaiser Permanente Northwest Division and Northwest Permanente PC, Oregon, USA
}

\begin{abstract}
Of growing concern over fehovah's Witnesses' (FWs) refusal of blood is the intrusion of the religious organisation into its members' personal decision making about medical care. The organisation currently may apply severe religious sanctions to $\mathcal{F W s}$ who opt for certain forms of blood-based treatment. While the doctrine may be maintained as the unchangeable "law of God", the autonomy of individual $\mathcal{F W}$ patients could still be protected by the organisation modifying its current policy so that it strictly adheres to the right of privacy regarding personal medical information. The author proposes that the controlling religious organisation adopt a "don't-ask-don't-tell" policy, which assures fWs that they would neither be asked nor compelled to reveal personal medical information, either to one another or to the church organisation. This would relieve patients of the fear of breach of medical confidentiality and ensure a truly autonomous decision on blood-based treatments without fear of organisational control or sanction.
\end{abstract}

(Fournal of Medical Ethics 1999;25:463-468)

Keywords: Autonomy; confidentiality; privacy; blood transfusion; Jehovah's Witnesses; refusal of medical care

\section{Introduction}

In the previous parts of this series, ${ }^{12}$ I presented information that one of the most serious problems in the biomedical ethics of the refusal of life-saving blood treatment by Jehovah's Witnesses (hereafter "JWs") is the controlling intervention of the church organisation (Watch Tower Bible and Tract Society, hereafter "WTS") in personal medical decision making of individual JWs. Two major components of organisational control compromise the autonomy of JW patients: 1) information control; and 2) policy to penalise members who dissent by accepting blood or advocating freedom to choose blood-based treatment. In part $2{ }^{2}$ I suggested a physician's approach to the individual JW patient that could moderate such information control and promote autonomous thinking and decision making. In part 3 , I present a petition that the controlling church organisation, the WTS, while maintaining its fundamental doctrine of refusal of blood, demonstrate the genuineness of its position of recognising and respecting the patient's true autonomy by making needed policy modifications. This discussion pertains to the tension between the protection of autonomy and confidentiality of individual organisational members (JW patients), and the stringent organisational (WTS) policy that controls the individual life of members.

\section{Blood transfusion as a free choice without control or sanction}

An important development since the previous parts of this series were written was the public agreement made in March 1998 between the WTS and the government of Bulgaria at the European Commission of Human Rights. In this agreement, the religious organisation declared that its members "have free choice" to receive blood transfusions "without any control or sanction on the part of the association". ${ }^{3}$ This is significant since for many years, JWs who wilfully received blood transfusions and did not repent have been excommunicated ("disfellowshiped") and ostracised. This is considered the most severe religious sanction of this religion. In his response to the previous parts of this series, $\mathrm{Mr}$ Malyon of the JW hospital liaison committee, Luton, Bedfordshire, in the UK, quoting the charter accepted by the Bulgarian government, stated that the WTS "may not exercise control over free will of believers but allows them to exercise their conscience consistent with godly Bible principles". He also states that the WTS does not "arbitrarily apply sanctions in connection with the medical care that Jehovah's Witnesses conscientiously seek for themselves and children", and this, according to him, is the established belief of JWs internationally. ${ }^{4}$ What is not at all clear is how the WTS can reassure JWs that they have such free choice of medical care as long as it enforces the traditional policy of excommunicating and/or 
ostracising those members, such as reform JWs, who disagree with the prevailing blood policy and who advocate free choice of medical treatment. According to reform JWs, these WTS statements could be interpreted to mean that each member may exercise his or her conscience to choose which blood components are acceptable in medical treatment, since there are no specific "godly Bible principles" that dictate what is acceptable among such components. On the other hand, the statements allow the WTS to "non-arbitrarily apply sanctions" and to continue to "exercise control over free will" despite their ostensibly amicable posture.

As of this writing, the WTS has been silent on this subject in its official publications, including the two official magazines, The Watchtower and Awake! which are intensely studied every week by JWs worldwide. Besides Malyon's, there have been several public comments by WTS spokesmen on this issue; a few internet posts by the WTS, ${ }^{5}$ a radio interview of a WTS official by the $\mathrm{BBC}^{6}{ }^{6}$ and a letter from a WTS official in The Lancet $^{7}$ So far, all indicate that the WTS has not changed its fundamental policy of blood refusal, while insisting that the members have freedom to make their own medical decisions regarding the acceptability of blood-based treatment.

Malyon indeed implied that JWs have free choices. He stated "each Witness chooses for himself" which of the various blood fractions to receive. ${ }^{8}$ This may sound as if JWs have complete freedom to choose, but Malyon told only a partial truth. The current organisational policies mandate that individual JWs may not freely decide for themselves from which fractions they may choose. For example, they may choose from the approved fractions such as albumin and globulin, but may not choose from prohibited fractions such as plasma or red blood cells. The choice has been decided in advance by the WTS. If a JW were to choose from the latter group of fractions, he would be subjected to some form of discipline, including being stigmatised or even experiencing the extreme of expulsion. If this is what the WTS means by "free choice", it is an entirely alien concept to most outsiders.

Malyon ${ }^{8}$ quoted On Liberty by John Stuart Mill: "Each is the proper guardian of his own health, whether bodily or mental and spiritual. Mankind are the greater gainers by suffering each other to live as seems good to themselves, than by compelling each to live as seems good to the rest." Malyon apparently intends that Mill's statement apply to JWs' right to freedom to refuse blood visa-vis medical and legal authorities, but the same statement should also be applied to JW' right to freedom to accept blood vis-a-vis the governing authority of the WTS. Mill also wrote just before the above quote as follows: "No society in which. these liberties are not, on the whole, respected, of free, whatever may be its form of government; an: none is completely free in which they do not exisf absolute and unqualified. The only freedor which deserves the name, is that of pursuing ou own good in our own way, so long as we do nog attempt to deprive others of theirs, or impedee their efforts to obtain it." 9 This statement should not be preempted by the WTS authority.

\section{Continuing ethical dilemma}

We physicians have an ethical responsibili towards our JW patients to be fully reassured of their autonomous decision making without coetos cion in regard to blood-based treatment. Jehovah Witnesses should have free choice literally "with out any control or sanction on the part of the association", as the WTS declared publicly. ${ }^{3} \vec{s}$ long as the traditional policy is in force, whicm authorises disfellowshiping and shunning of those who openly receive certain blood fractions, the medical community cannot be reassured of the patient's autonomy. A WTS official in the BBढ interview argued that a JW who accepts bloos would never be automatically disfellowshiped. If he expresses remorse and repentance beforo judicial committee, he will not be punished wit the most severe religious sanction. $\mathrm{He}$ also argue that unrepentant JWs who received blood are dis fellowshiped not because of the fact that the received blood, but because they abandoned the doctrine of the religious organisation. ${ }^{6}$ This argu? ment, however, directly contradicts the WTS public declaration that JWs have freedom to choose blood transfusions, because the end resule of exercising and maintaining the free choice disfellowshiping, the most severe religious sancis tion. Whether the sanctions are automatic or nof whether the doctrine is abandoned or not, is irret evant to the fundamental freedom of choice; if the end result of the choice is the sanction, that choic cannot be free. Would WTS officials consider that JWs are free to preach in a country if, upon doing so, they were required to express remorse and repentance before a court in order to avoid penafus ties?

Malyon $^{4}$ also argued that each JW joined the religion "within the framework of a way of life freely chosen", implying that once a person made a free decision to join the religion, he must havto consented to the policies and agreed to be subjeç to disciplinary action of the organisation as a freo choice. Malyon argued that such disciplinaro measures are justified, using a comparison with 
the disciplinary action of the General Medical Council against doctors who violate professional codes. There are several flaws in this argument.

First, as discussed in part 1, most JWs are not fully informed of the details and extent of the blood policy at the time of their baptism. For example, even though they always recite the doctrine "The Bible says to abstain from blood, which obviously means not taking it into our body at all", most JWs do not know the exact classification of acceptable and unacceptable blood components. Nor have they been adequately informed of the various benefits of blood-based treatments in their official magazines. Moreover, there are many JWs who were baptised as minors, some as young as eight years, or who were baptised before the current policies and rules were implemented or changed. Why should they be subjected to disciplinary measures for violating "codes" of which they were not fully informed and which they did not fully understand and commit to?

Second, most JWs joined their religion to live by Bible principles and serve God. During their membership, some JWs may come to realise, from their own Bible study, that the blood policy has no biblical basis. For those JWs, the blood policy can be challenged by invoking the higher authority of Bible principles. That is exactly what the dissident JWs are doing, as reviewed in part $1 .{ }^{1}$ Is it morally appropriate for an organisation which claims The Bible and God as the highest authority to punish those members who challenge the policy based on The Bible and God's messages as they understand them? It should also be noted that leaving the religion is an extremely difficult option for dissidents and reformers because of the sanctions that may be applied for dissenting and leaving - the same sanctions that enforce the blood policy. Those who leave may be declared to have "disassociated" themselves, and they are shunned exactly as if they were disfellowshiped. If I use Malyon's analogy, doctors should be allowed to challenge the General Medical Council's codes of conduct if such codes held a possibility of violating the constitution of the nation. At least those doctors would not, and should not be sanctioned with the harshest penalty just because they challenged the constitutionality of the codes. The WTS, on the other hand, prohibits similar challenges with a threat of sanction by its harshest penalty.

By word and religious practice since the promulgation of its policy in 1945, it is clear that the WTS continues to compromise true autonomy of JW patients by systematically applying pressure and sanctions, despite the public appearance of respect for free choice of the members, as expressed at the European Commission of Human Rights. ${ }^{3}$

\section{Root cause of compromised autonomy}

In part 2, I reviewed case reports in which organisational pressure resulted in decisions of $\mathrm{JW}$ patients to accept blood-based treatment being reversed. This influence comes in various forms. Typically, family members, friends and congregational members gather around the patient and "watch over their shoulder" the medical care the patient receives. Even if there is no intentional "monitoring", the peer pressure is nevertheless enormous. Another common situation is the intervention of the hospital liaison committee, which consists of church elders delegated to promote so-called "no-blood" medicine. Although its primary mission is to assist JW patients to find doctors and hospitals willing to accept patients for no-blood treatment, members of the committee may also visit JW patients. While they may give the patient "moral support", the influence of their presence on the patient is known to be tremendous. Case reports reveal JW patients have changed their earlier decision to accept blood treatment after a visit from the elders. ${ }^{10}$ After the patient is discharged from the hospital, congregation elders may inquire as to what treatment he received. Even without such interrogations, the patient may feel obliged to volunteer the information just to clear any suspicion that he might have received blood. All these factors result in pressure to refuse blood-based treatment.

These observations indicate that what allows organisational pressure to compromise the autonomy of JW patients is interference with the patient's privacy and confidentiality, the basic codes of ethics. While JWs generally demand and respect privacy in personal matters when it comes to outsiders, privacy inside the religious community is not a priority. This is realised from the teaching published by the WTS in 1987, advocating that JWs working in the medical field breach the confidentiality of JW patients who consent to medical treatment prohibited by the WTS. ${ }^{11}$ Although there has been a growing consensus in recent years in the medical community and in society in general that a patient's confidentiality is paramount, such a viewpoint is conspicuously absent from JW teaching.

\section{Possible solution with minimal change in policy}

As I showed in part $1,{ }^{1}$ the religion of Jehovah's Witnesses has undergone a number of doctrinal changes which affect the life and death of 
members, including lifting bans on immunisation and organ transplantation. In view of this, it is conceivable that the WTS may reform its blood policy at some point in the future for reasons similar to those used to rescind the ban on immunisation and organ transplantation. Malyon seems to suggest this possibility by stating the JWs' "willingness to reconsider and re-evaluate their views in very positive ways". ${ }^{8}$ Nevertheless, it is not likely to happen in the near future judging by recent WTS statements. In the meantime, premature deaths of JWs continue to be reported in various parts of the world, due to refusal of life-saving blood-based treatments. ${ }^{12}$ Is there any modification to the current policy that would protect patients' autonomy, and thereby prevent some premature deaths due to misinformation and organisational pressure to refuse life-saving treatment, and at the same time not oblige the WTS to compromise its biblical stance?

In an attempt to address this crucial question, I hereby propose that the controlling church organisation, as evidence of the genuineness of its declaration of respect for the autonomy of JW patients, adopt a simple policy to promote respect for patient's privacy and confidentiality, one of the most fundamental elements of autonomy, and promote this policy among JWs worldwide. As shown in the previous section, the most coercive influence comes from the fear of breach of patient confidentiality. The following proposed guidelines focus on this problem.

First, congregational leaders would do well to exercise the utmost respect for each patient's privacy and confidentiality, and refrain from prying questions. Second, the WTS could encourage JWs to keep their own medical treatment a matter of privacy. Members should be advised that they are not required to disclose medical information to fellow JWs and congregational leaders. They should be duly informed of potential consequences of any leak of confidential information, even through casual and well-intended discussion.

If the WTS genuinely respects the autonomous decisions of its members, it could demonstrate this by counselling members to show similar respect for one another's privacy and to avoid any undue questioning or prying into a patient's choice of treatment. It could also publicly retract the teaching of 1987 that condoned breach of medical confidentiality - a teaching inharmonious with their recent public assurances of freedom of choice for members at the European Commission of Human Rights.

In line with this proposal, the hospital liaison committee's function should be limited to providing necessary information to physicians and patients; its members should no longer interven $\frac{3}{6}$ in individual patients' care unless they are explidy itly requested to do so by the patient or physiciaf.

In essence, I propose that the church organis? ation and congregational leaders "not ask" abot? matters that might infringe upon patient privacy and confidentiality in medical care, and that patients "not tell" or disclose personal medic information. Thus, this policy may be called “don't-ask-don't-tell” policy.

Maintaining privacy among family members naturally difficult, and casual breach of patient confidentiality to the spouse, parents and childre $\vec{f}$ has been quite common. While this may not be op problem in most cases, it should be recognise that in some circumstances, such as the medica? care of JWs, assurance of non-disclosure, even family members, is essential. This is particularl true when there is conflict of interest or incongrio ity in value judgment among family members.

\section{Precedent of similar policy in Jehovah's Witnesses}

Although this proposal may appear to suggest $\frac{\mathbb{Q}}{\mathrm{C}}$ compromise between the controlling WTS and the dissident JWs who propose a fundame reform of the blood policy, more important could lend the WTS a viable alternative to furis mental doctrinal changes, which might cause widespread confusion in the religion and be totaly unacceptable to the leaders. Whether such modis fication of the blood policy is feasible and can be integrated in the JW religion is, of course, sole up to its governing body, who have absolute authority of policy making and doctrinal changes. This religion has a long history of advising all JW of their scriptural responsibility to report wron doers, regardless of the consequences to then selves. The policy to promote respect for ind vidual privacy and confidentiality would be significant departure from its tradition.

However, this departure is not nearly as big as 유 might seem; a policy similar to the one I have prof posed here has already been adopted by the WTS and is still effective in the JW community. In 1970 the WTS decided that various sexual practicis between married couples were forms of "fornicas tion". In particular they were concerned with orgi and anal sex. They indicated that JWs were 10 report themselves and their mates to the elders of they had been practising these forms of sex. The elders were to disfellowship anyone who refused to repent. There are reports of broken marriages and legal problems as a result of these directive For example, a JW woman divorced her non-J husband because he insisted on oral sex, and the 
man took the WTS to court for unduly influencing his wife to divorce him. The WTS largely abandoned this doctrine in 1978, and issued an explicit "don't-ask-don't-tell” policy in its official magazine in 1983 as follows:

"How about sexual activity between married couples within the marriage bond? It is not for the elders to pry into the intimate lives of married Christians. However, The Bible certainly enters into their lives. Those who would "keep walking by spirit" should not ignore the Scriptural indications of God's thinking. And they will do well to cultivate a hatred for everything that is unclean before Jehovah, including what are clearly perverted sexual practices. ... it is not for elders to "police" the private marital matters of couples in the congregation. However, if it becomes known that a member of the congregation is practising or openly advocating perverted sex relations within the marriage bond, that one certainly would not be irreprehensible, and so would not be acceptable for special privileges, such as serving as an elder, a ministerial servant or a pioneer. Such practice and advocacy could even lead to expulsion from the congregation." 13

If this precedent holds, the WTS could publish a similar article, instructing JWs that "it is not for elders to police the private medical matters of spiritual brothers and sisters in the congregation". They could even say that "if it becomes known that a member of the congregation is receiving blood or openly advocating blood transfusions, that one certainly would not be irreprehensible. Such practice and advocacy could even lead to expulsion from the congregation". This modification need not mean any compromise of their fundamental doctrine of blood refusal, any more so than the above modification compromised their doctrine of fornication. It is understandable that for a cohesive religious organisation, a reporting system of "wrongdoers" might be viewed as a necessity. However, here I am proposing that deeply private matters such as medical treatment in hospital rooms be exempted from such reporting in the same way as are sexual practices among married people in their bedrooms.

\section{Common goal of autonomy and freedom in refusal of blood}

The goal of this proposed "don't-ask-don't-tell" policy in the medical care of JWs is to promote the patient's autonomy and free choice through strict observation of the patient's confidentiality, irrespective of the controversial blood doctrine itself.
It should be noted that respect for the patient's autonomy and freedom of choice has been one of the chief pillars in the WTS's argument to justify the policy of blood refusal. This stance is symbolically displayed in the title of Malyon's recent article. ${ }^{8}$ In this sense, the WTS has been a staunch defender of patient rights of self-determination and autonomy. Therefore the goal of protecting the patient's autonomy and free choice should not be negated by either party - not by the WTS, which has publicly advocated this right, in the form of the right to refuse blood, nor by reform JWs who wish to exercise their personal freedom to make medical decisions while maintaining their good standing as JWs. This should be a common goal of parties on both sides of the issue, and thus be achievable. And if JWs are all refusing blood truly of their own free will, there should be nothing compromised by the WTS in adopting this policy - JWs will continue to refuse blood regardless of the confidentiality issue. On the other hand, if the WTS continues to teach the JW community to breach medical confidentiality ${ }^{11}$ and report "wrongdoers" by ignoring this proposal, the medical community will have little choice but to conclude that the WTS's claimed interest in patient autonomy is not genuine, and that its leaders' true intent is to ensure that all the followers refuse blood transfusions irrespective of their personal choice.

One Bible passage seems to be particularly pertinent for WTS leaders who claim respect for individual autonomy: "Not that we are the masters over your faith, but we are fellow workers for your joy."1+ The Bible also says: "Do you, however, the one teaching someone else, not teach yourself? You, the one preaching 'Do not steal', do you steal?" ${ }^{15}$ Similarly, if the WTS leadership teaches religious freedom and freedom of choice, one must ask: "You, the one preaching freedom of choice, do you deny it to others?"

\section{Wider application of don't-ask-don't-tell policy}

This policy could also be applied in several other situations where patients' autonomy and freedom are threatened by the casual leak of confidential medical information. Where any community or group has a strong value judgment regarding a certain medical condition or treatment which is so strong that any deviation may not be tolerated, a “don't-ask-don't-tell" policy can protect patients' privacy and confidentiality, and thus autonomy, while the value judgment remains unchallenged. Besides sexual practices between married couples, as already mentioned, the policy can also be 
applied in a community where highly controversial doctrine predominates regarding, for example, beginning-of-life and end-of-life decisions. The diagnosis of mental illness in certain parts of the world (Japan, for example) creates a strong prejudice, which causes many patients to delay their visit to a psychiatrist. While it takes years of public education to resolve such underlying societal prejudice, adopting a "don't-ask-don't-tell" policy in the community can free those psychiatric patients and families from undue societal pressure, even without removing such societal prejudice.

This policy in general terms could also promote the awareness of medical confidentiality among patients and non-medical people. While respect for patients' confidentiality by medical professionals is considered an integral part of our professional ethics, little has been discussed about the role of patients themselves in protecting their own medical confidentiality. Enforcement of blood refusal among JWs discussed here illustrates the importance of this point. Unless a physician's effort to respect patient confidentiality is supported by patients themselves, the integrity of patients' autonomy cannot be ensured solely by the physician. The medical community has a responsibility to educate the public, including JW patients, in this respect.

\section{Conclusion}

While WTS officials, including Malyon ${ }^{4}$ may not agree with reform JWs on an immediate change of their core doctrine of blood refusal, one important value should be agreed upon: the right of each patient to autonomy and freedom of selfdetermination. They can also likely agree on the need to respect a patient's privacy and confidentiality, which is the essential element of autonomy. I hereby petition the controlling organisation of JWs to adopt and publish a "don't-ask-don't-tell" policy regarding JWs' medical care. The medical community should also request the leaders of this religion to promote respect for the privacy and confidentiality of individual JW patients. It is this author's sincere hope that the suggested modification of the WTS's policy will ensure the true autonomy and freedom of choice in medical care for all JW patients.

\section{Acknowledgement}

I thank several members of the Associated Jehovah's Witnesses for Reform on Blood (AJWRB) for their extensive review of the manu- script and valuable discussion in preparation o this paper. Regrettably, the identity of current members of the religion cannot be disclosed pubs. licly due to fear of retribution by the WTS.

\section{Disclaimer}

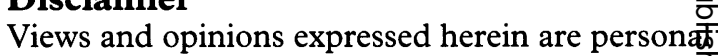
and do not reflect those of Kaiser Permanente an $\vec{\Phi}^{\circ}$ Northwest Permanente PC.

Osamu Muramoto, MD, PhD, is a member of the Regional Ethics Council at Kaiser Permanentise Northwest Division, and a Neurologist at Northwest Permanente PC. Address correspondence to: Kais East Interstate Office, 3414 NW Kaiser Center Drive Portland, Oregon 97227, USA.

\section{References and notes}

1 Muramoto O. Bioethics of the refusal of blood by Jehovah' Witnesses: part 1. Should bioethical deliberation considet dissidents' views? Fournal of Medical Ethics 1998;24:223-30.

2 Muramoto O. Bioethics of the refusal of blood by Jehovah Witnesses: part 2. A novel approach based on ration non-interventional paternalism. Fournal of Medical Ethics 1998 24:295-301.

3 Muramoto O. Jehovah's Witnesses and blood transfusione $\vec{e}$ Lancet 1998;352:824. The original document is available forfo URL: http://194.250.50.201/eng/E276INFO.148.html. Gêntmunique issued by the Secretary to the European Commisictin of Human Rights. INFORMATION NOTE No 148 of the 276th Session of the European Commission of Human Rights (Strasbourg, Monday 2 March - Friday 13 March 1998). Thr full text of the "friendly settlement" in French is available froet URL: http://194.250.50.201/eng/28626.28.html.

4 Malyon D. Transfusion-free treatment of Jehovah's Witnesse respecting the autonomous patient's motives. Fournal of Medical Ethics 1998;24:376-81.

5 Watch Tower Bible and Tract Society: press release. PR New wire April 27, 1998 and October 9, 1998. PR Newswire (http: 娄 www.newswire.com)

6 Transcript of interview with The Liberal Elder and PaG Gillies, spokesman for WTS, by Roger Bolton on Sunday, BBE Radio 4, 1998 Jun 14.

7 Wilcox P. Jehovah's Witnesses and blood transfusion. Lanç 1999;353:757-8

8 Malyon D. Transfusion-free treatment of Jehovah's Witnesses respecting the autonomous patient's rights. Fournal of Medicp. Ethics 1998;24:302-7.

9 Mill JS. On liberty. Chicago: Henry Regnery Company, 1952 18.

10 See reference 2: 296

11 Anonymous. "A time to speak"- when? The Watchtower 1987 Sept 1:12. For detailed discussion of this teaching, reference $1: 225$.

12 Exact statistics of JWs who prematurely died due to blogd refusal is unknown. Partial list of those cases that gatherea attention of news media is available at URL: http www. abaweb.com/WATCHTOWERvictimsMEMORIAI/ Cases which never surfaced in news media are likely to be subj stantially more than this.

13 Anonymous. Honor godly marriage. The Watchtower $1983 \mathrm{M}$ 15: 30-1.

14 The Bible [New World translation]. Brooklyn: The Watên Tower Bible and Tract Society of New York, Inc, 1984: 2 Cod inthians $1: 24$.

15 The Bible [New World translation]. Brooklyn: The Watch Tower Bible and Tract Society of New York, Inc, 1984 Romans 2:21. 